\title{
Logistic planning for the use of renewable fuels in the energy complex of the region
}

\author{
Denis Nefedov $^{l}$, Karolina Ketova ${ }^{l}$ and Ivan Rusyak ${ }^{l}$ \\ ${ }^{1}$ Kalashnikov Izhevsk State Technical University, Studencheskaya str., 7, Izhevsk, 426069, Russia
}

\begin{abstract}
The article discusses the solution to the problem of logistics planning for the use of renewable fuels in the energy complex. The technology used is the production of thermal energy from wood waste. Logging and wood processing enterprises, which are a source of wood waste, wood waste processing stations, which produce chips and pellets, as well as coal-fired boilers, which generate heat energy, are considered as objects participating in the process of heat energy production. The structure of the optimal placement of participants in the process of heat energy production from wood waste is built on the example of the Udmurt Republic. The economic criterion for minimizing the cost of heat production at all coal-fired boiler houses in the region, taking into account the costs of the supply of wood waste, as well as the production and supply of chips and pellets, was chosen as an optimization criterion. In the numerical solution, a genetic algorithm with real coding was applied, and the calculations were parallelized. It was found that in the conditions of the Udmurt Republic, the organization of pellet plants turned out to be inappropriate. The optimal placement option assumes the presence of 6 points for the preparation of chips. This makes it possible to provide fuel for all coal-fired boiler houses located in the region. The average cost of producing heat energy using wood fuels for all the boiler houses under consideration was 897 rubles / Gcal, which is $76,6 \%$ lower than the corresponding indicator for heat energy obtained from coal.
\end{abstract}

\section{Keywords}

Optimal location, wood waste, wood chips, pellets

\section{Introduction}

The use of renewable fuels in the modern world is of great practical importance. The need to use alternative types of energy is due to the active growth of the world economy, and, as a result, an increasing need for energy resources. The other side of the issue is the growing problems with the environmental situation. The use of renewable fuels helps maintain a balance in ecosystems. The benefits of renewable fuels are detailed in C. King. [1].

One of the types of renewable fuels in the conditions of the Russian Federation is wood waste from logging and timber processing. The potential of these fuels for the Russian Federation was estimated in the work of the authors E. Solomin, A. Ibragim and P. Yunusov [2]. The prospect of using wood waste in gasified areas is analyzed in the article by E. Kashin, R. Safin and V. Didenko [3].

The use of wood waste in the energy complex with the practical implementation of the scheme of its optimal logistics planning allows you to obtain a positive economic effect. The scale of the use of these types of fuel is determined by various factors: the concentration of wood waste in the required place, the possibilities of selling the obtained heat energy, technological and logistic schemes, labor and material resources. Logistic planning, which consists in building the optimal structure of production and the location of enterprises for processing raw materials, allows the most rational use of available

III International Workshop on Modeling, Information Processing and Computing (MIP: Computing-2021), May 28, 2021, Krasnoyarsk, Russia

EMAIL: denisnefedov1@yandex.ru (Denis Nefedov); ketova_k@mail.com (Karolina Ketova); primat@istu.ru (Ivan Rusyak) ORCID: 0000-0003-4569-3376 (Denis Nefedov); 0000-0001-7143-1930 (Karolina Ketova); 0000-0001-8584-8884 (Ivan Rusyak)

(C) (i) (C) 2021 Copyright for this paper by its authors.

Use permitted under Creative Commons License Attribution 4.0 International (CC BY 4.0).

CEUR Workshop Proceedings (CEUR-WS.org) 
resource opportunities to minimize costs and maximize profits. The issues of logistic planning and determination of the optimal location of objects distributed over the territory are set forth in the work of M. Daskin [4].

Approaches using new information technologies and mathematical methods of production and logistics of wood fuel for the development of bioenergy in Russia are presented in the works of A. Sokolov and V. Syunev [5], K. Ketova and E. Trushkova [6].

For the possibility of using renewable fuels at the regional level, concepts of fuel supply of local heat supply systems with renewable fuels are being developed (see, for example, [7]).

In this work, we will study the issue of logistics planning when using wood waste to obtain heat energy supplied to the heat supply system of the region. We will give numerical calculations using the example of the Udmurt Republic (UR).

\section{Materials and research methods}

\subsection{Problem statement and mathematical model of the problem}

Let us formulate a meaningful statement of the logistic problem of organizing the production of fuel from wood waste and its delivery to points of consumption. We will use wood waste generated because of the work of logging and timber processing enterprises. In our task, this waste is a raw material.

Wood waste from the logging and woodworking industries has high moisture content, low heating value and is inconvenient for delivery and direct combustion at heat sources. Therefore, the processing of primary wood pulp into a more technologically advanced fuel is required. Fuel chips obtained by shredding and natural drying of wood waste have the minimum production costs. However, chips have a low density, so it is economically impractical to transport them over long distances exceeding 20-30 $\mathrm{km}$. Wood pellets are a much more energy-concentrated type of fuel. To obtain them, additional operations of drying, crushing and pressing of raw materials are required. It is already economically feasible to transport this type of fuel over a distance of $100 \mathrm{~km}$ or more.

Thus, wood waste is converted into two types of intermediate products: wood chips and pellets.

There are a number $K$ of heat production points - heat sources. As heat sources, we will consider boiler houses that work with coal. Chips $(m=1)$ and pellets $(m=2)$ are used to generate heat energy, which are interchangeable fuels (respectively, $M=2$ types of fuel). For the production of fuel, raw materials are used, prepared at the points of raw material accumulation, the total amount of which is equal to $I$. It is required to find the volumes of production of chips and pellets in each of $J$ production points (Figure 1:).

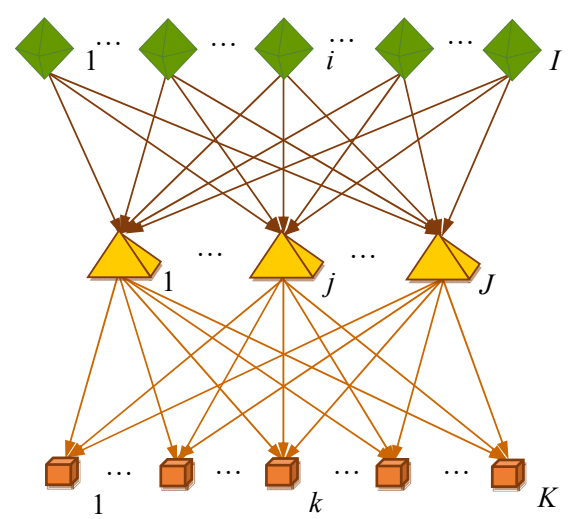

Figure 1: Scheme of the relationship between logging and wood processing enterprises, points for the production of chips and pellets, as well as coal-fired boilers

Possible positions of the points for the production of chips and pellets are determined in advance, while they may or may not coincide with the territorial location of accumulation points of logging and wood processing waste and the location of coal-fired boilers, in which heat energy is produced. The 
objective function of the problem is the total cost of heat production at all boiler houses, taking into account the cost of production and supply of wood chips and pellets:

$$
\begin{gathered}
C=\hat{C}+\tilde{C}, \\
\tilde{C}=\sum_{j=1}^{J} \sum_{m=1}^{2} F_{j}^{m}\left(V_{j}^{m}\right)+\tau \sum_{i=1}^{I} \sum_{j=1}^{J} \sum_{k=1}^{K} \sum_{m=1}^{2} \eta^{m}\left(\alpha^{m} g_{i j}^{m}+g_{j k}^{m}\right) x_{i j k}^{m} D_{k}, \\
\tilde{C}=\sum_{k=1}^{K} \sum_{m=1}^{2} E_{k}^{m}\left(D_{k}^{m}\right) .
\end{gathered}
$$

In the statement of the problem (1)-(3): $C$ are total costs of heat production, rubles/year; $\hat{C}$ are costs of transportation of logging and wood processing waste, production of chips and pellets and their delivery to boiler houses, rubles/year; $\tilde{C}$ are costs for the processing of chips and pellets into heat energy in boiler houses, rubles/year; $V_{j}^{m}$ is the volume of production of chips $(m=1)$ and pellets $(m=2)$ at the $j$ th point $\left(\mathrm{m}^{3} /\right.$ year); $D_{k}^{m}$ is the volume of heat energy production at the $k$ th boiler house using wood chips or pellets, Gcal/year; $F_{j}^{m}\left(V_{j}^{m}\right)$ are costs of processing wood waste into chips or pellets at the $j$ th point of their production, rubles/year; $E_{k}^{m}\left(D_{k}^{m}\right)$ are costs for the processing of chips and pellets into heat energy at the $k$ th boiler house, rubles/year; $g_{i j}^{m}$ are unit costs for the transportation of wood waste for the production of chips or pellets between the $i$ th point of accumulation of wood waste and the $j$ th point of production of chips or pellets, rubles $/ \mathrm{m} 3 ; g_{j k}^{m}$ are unit costs for the transportation of wood chips or pellets for the production of heat energy between the $j$ th point of their production and the $k$ th boiler house, rubles $/ \mathrm{m}^{3} ; x_{i j k}^{m}$ is the share of demand of the $k$ th boiler house, satisfied by the consumption of wood chips $(m=1)$ or pellets $(m=2)$, produced by the $j$ th point of their production using wood waste from the $i$ th accumulation point; $\tau$ is caloric equivalent, t f.e./Gcal; $\alpha^{m}$ is consumption coefficient of wood waste unit for the production of a fuel unit in the form of chips or pellets, units/t f.e. (units $=\{t$, $\left.m^{3}\right\}$, $\mathrm{t}$ f.e. is ton of equivalent fuel); $\eta^{m}$ is coefficient of the ratio of the total volume of heat energy production on chips or pellets to its useful output; takes into account the costs of chips or pellets for the own needs of the boiler house and its other costs, $t$ f.e./Gcal.

The controlled variables of the task are variables $x_{i j k}^{m}$ that determine the share of the boiler house demand for wood chips and pellets.

The costs $F_{j}^{m}\left(V_{j}^{m}\right)$ of processing wood waste into chips and pellets are determined because of technical and economic calculations:

$$
F_{j}^{m}\left(V_{j}^{m}\right)=a_{j}^{m} V_{j}^{m}+A_{j}^{m} \Theta\left(V_{j}^{m}\right), \quad j=\overline{1, J}, \quad m=1,2,
$$

where $a_{j}^{m}$ are specific conditionally fixed costs for the production of chips or pellets at the $j$ th point, rubles/t f.e.; $A_{j}^{m}$ are conditionally fixed costs for the production of chips and pellets at the $j$ th point, rubles/year; $\Theta\left(V_{j}^{m}\right)$ is Heaviside function.

The cost of processing wood chips and pellets into heat energy is determined by the formula:

$$
E_{k}^{m}\left(D_{k}^{m}\right)=b_{k}^{m} D_{k}^{m}+B_{k}^{m} \Theta\left(D_{k}^{m}\right), \quad k=\overline{1, K}, \quad m=1,2,
$$

where $b_{k}^{m}$ are specific conditionally fixed costs for the production of a unit of heat energy at the $k$ th boiler house, rubles/Gcal; $B_{k}^{m}$ are conditionally fixed costs for the entire production of heat energy at the $k$ th boiler house, rubles/year.

The following ratios are accepted as restrictions:

$$
\begin{gathered}
V_{j}^{m}=\tau \eta^{m} \sum_{i=1}^{I} \sum_{k=1}^{K} x_{i j k}^{m} D_{k}, \quad j=\overline{1, J}, \quad D_{k}^{m}=D_{k} \sum_{i=1}^{I} \sum_{j=1}^{J} x_{i j k}^{m}, \quad k=\overline{1, K}, \\
\tau \alpha^{m} \eta^{m} \sum_{j=1}^{J} \sum_{k=1}^{K} x_{i j k}^{m} D_{k} \leq S_{i}^{m}, \quad \sum_{i=1}^{I} \sum_{j=1}^{J} \sum_{m=1}^{2} x_{i j k}^{m}=1, \quad x_{i j k}^{m} \in[0 ; 1], \\
i=\overline{1, I}, \quad j=\overline{1, J}, \quad k=\overline{1, K},
\end{gathered}
$$

where $D_{k}$ is the total volume of heat production in the $k$ th boiler house, Gcal/year; $S_{i}^{m}$ is the total volume of wood waste at the $i$ th point of their accumulation, $\mathrm{m}^{3} /$ year.

Relations (6) establish a balance between the output of chips and pellets at the points of their production and the need for chips and pellets of coal-fired boiler houses for the production of heat energy. The first inequality (7) determines the balance between the required volume of wood waste and the potential of the raw material base at logging and wood processing enterprises. The second expression (7) reflects the condition of satisfaction of chips and pellets for all considered boiler houses.

Another type of restrictions that have a significant impact on the choice of the optimal option for the location of production is associated with administrative regulators: tariffs and quotas. The use of these regulators increases the cost of transported resources, which is associated with restrictions on their movement. 
If we introduce a tariff for the transportation of wood waste for the production of chips and pellets between the $i$ th point of accumulation of wood waste and the $j$ th point of production of chips $(m=1)$ and pellets $(m=2)$ in the amount of $t_{i j}^{m}$, and the tariff for the transportation of wood chips and pellets between the $j$ th point of their production and $k$ th boiler house in size of $T_{j k}^{m}$, then the tariffed values of the corresponding unit transport costs will be calculated using the formulas:

$$
\left(g_{i j}^{m}\right)^{*}=\left(1+t_{i j}^{m}\right) g_{i j}^{m}, \quad\left(g_{j k}^{m}\right)^{*}=\left(1+T_{j k}^{m}\right) g_{j k}^{m} .
$$

If we introduce expressions for accounting for transportation quotas into the problem statement, then the original model should be supplemented with restrictions of the form:

$$
\tau \alpha^{m} \eta^{m} \sum_{j=1}^{J} \sum_{k=1}^{K} x_{i j k}^{m} D_{k} \leq \bar{S}_{i j}^{m}, \quad \tau \eta^{m} \sum_{i=1}^{I} \sum_{k=1}^{K} x_{i j k}^{m} D_{k} \leq \bar{V}_{j k}^{m} .
$$

In the restrictions (9), $\bar{S}_{i j}^{m}$ is the volume of transported, taking into account the introduction of transportation quotas, wood waste for the production of chips $(m=1)$ or pellets $(m=2)$ between the $i$ th point of wood waste accumulation and the $j$ th point of production of chips or pellets; $\bar{V}_{j k}^{m}$ is the volume of chips and pellets transported, taking into account the introduction of transportation quotas, between the $j$ th point of production of chips or pellets and the $k$ th boiler house.

Thus, the problem statement has the form (1)-(9). Consider a numerical algorithm for its solution.

\subsection{Algorithm for solving the problem}

The problem being solved is nonlinear. In the course of its solution, we will use the results obtained, in particular, in the works of researchers T. Rapcsak [8] and Q. Dong, T. Xu, J. Yang и Z. Zhou [9]. These works present the results of the study of nonlinear optimization problems based on the theory of genetic algorithms.

The sufficiently large dimension of the vector of the sought solutions hampers the search for the optimal solution in the problem under study. For example, for the conditions of the Udmurt Republic, the dimension of the original vector formed by the array of $x_{i j k}^{m}$ is 180,000 elements. To solve this problem, the results of the work of researchers P. K.-H. Phua, D. Ming, W. Fan and Y. Zhang [10] were used, where parallel algorithms are investigated to solve large-scale nonlinear optimization problems. Also, in the problem being solved (1)-(9) the objective function (1)-(3) is nondifferentiable.

A genetic algorithm with real coding was used, and the method of parallelizing computations was also applied (Figure 2:).

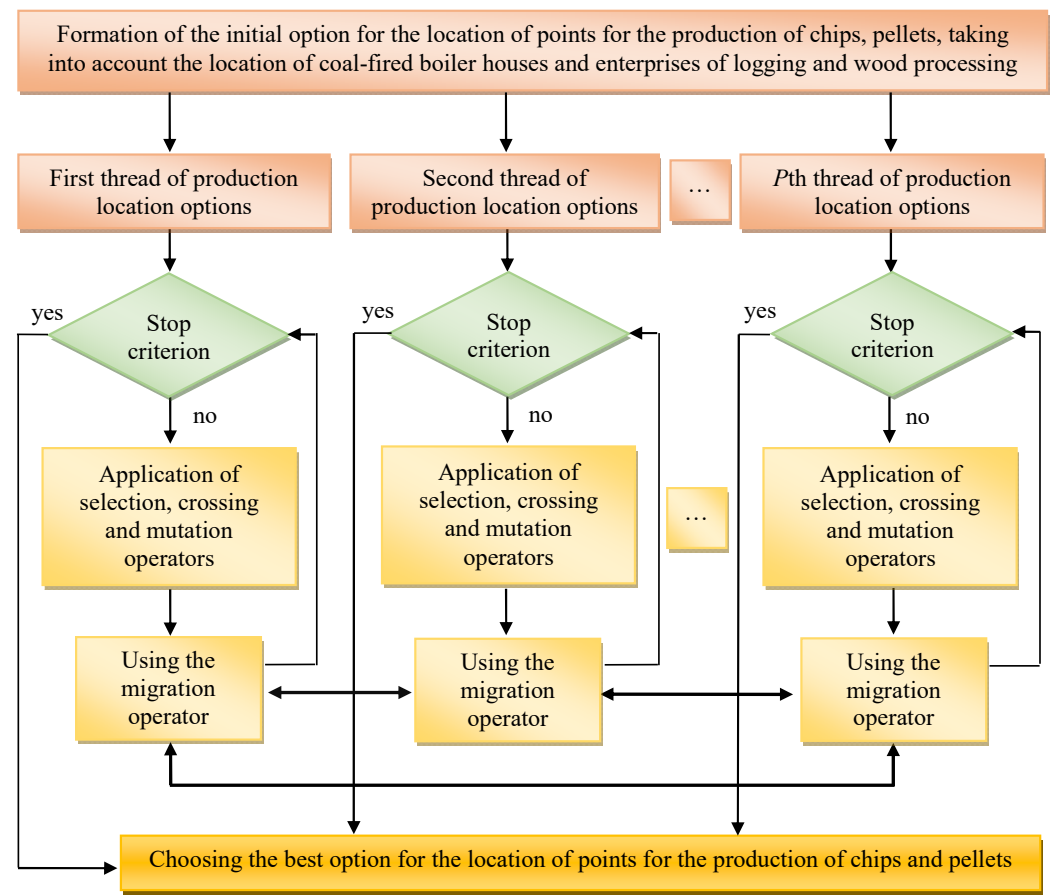

Figure 2: Algorithm for solving the problem 


\section{Research results}

We will consider the solution of the presented problem using the example of the Udmurt Republic. The territory of this region is almost half covered with forests, which implies the presence of the necessary amount of wood waste for the practical implementation of the problem.

The republic consists of 25 districts. Figure 3: presents graphs of the energy potential of waste from logging and wood processing enterprises. Figure 4: shows the annual demand of coal-fired boiler houses for fuel and the energy potential of wood raw materials by regions of UR in 2019.

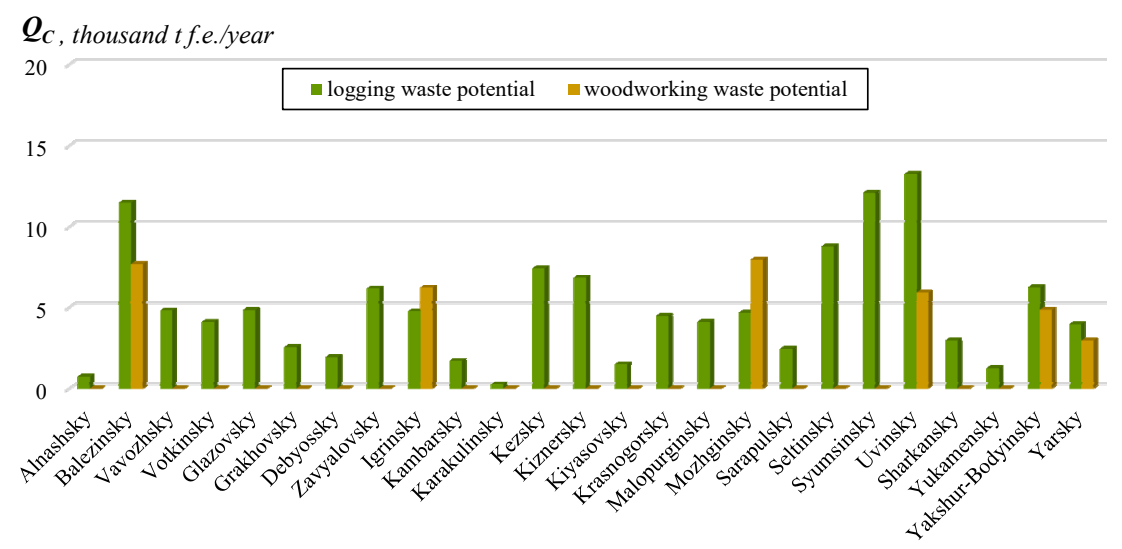

Figure 3: Distribution of the energy potential of logging and wood processing waste by regions of the UR in 2019

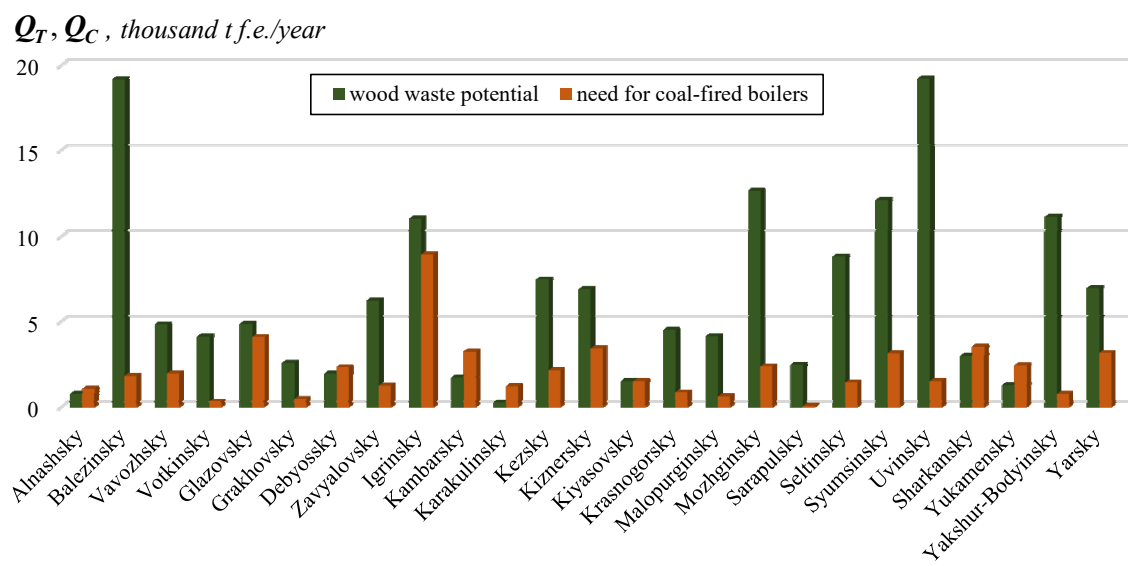

Figure 4: Annual demand of coal-fired boiler houses for fuel and energy potential of wood raw materials by regions of the UR in 2019

For UR it is necessary to transfer 60 coal-fired boiler houses to wood-based fuels: wood chips and pellets. The raw material for the production of wood chips and pellets is waste from logging and wood processing enterprises. Initial data on the needs of boiler houses for chips and pellets, stocks of wood waste, unit costs for transportation of raw materials and fuel are given in [7]. The total volume of heat supply in the considered boiler houses is $56.277 \mathrm{Gcal} /$ year. The points of accumulation of raw materials for the production of wood chips with a total potential of $55.960 \mathrm{~m}^{3} /$ year are located outside the settlements - next to the points of deforestation. The raw material base for pellets is determined by the amount of waste from a wood processing enterprise located in one of the regions of the UR (Balezino). The potential of this point for the accumulation of raw materials is $22.480 \mathrm{t} / \mathrm{year}$. The coefficient that determines the amount of wood waste required for the production of chips is $\alpha^{1}=3.759 \mathrm{~m}^{3} / \mathrm{t}$ f.e., for the production of pellets $-\alpha^{2}=3.644 \mathrm{t} / \mathrm{t}$ f.e. The ratio of the generated heat energy to its useful supply for wood chips is $\eta^{1}=1.232$, for pellets $-\eta^{2}=1.169$. Caloric equivalent $\tau=0.143 \mathrm{t}$ f.e./Gcal. 
When solving the problem, it was assumed that potential locations for the production of chips and pellets should be located in the same place where coal-fired boiler houses are located. At the same time, each boiler house can be supplied with either chips or pellets and only from one fuel production point. Also, a restriction was introduced that the wood waste of any five collection points is sufficient to produce chips and pellets in a volume that exceeds the need of any boiler house.

As a result of solving problem (1)-(9), an optimal variant of placement was obtained, in which 6 points for the preparation of chips provide fuel for all heat sources (see Figure 5:). The organization of pellet plants on the territory of the UR from the point of view of minimizing total costs turned out to be inexpedient

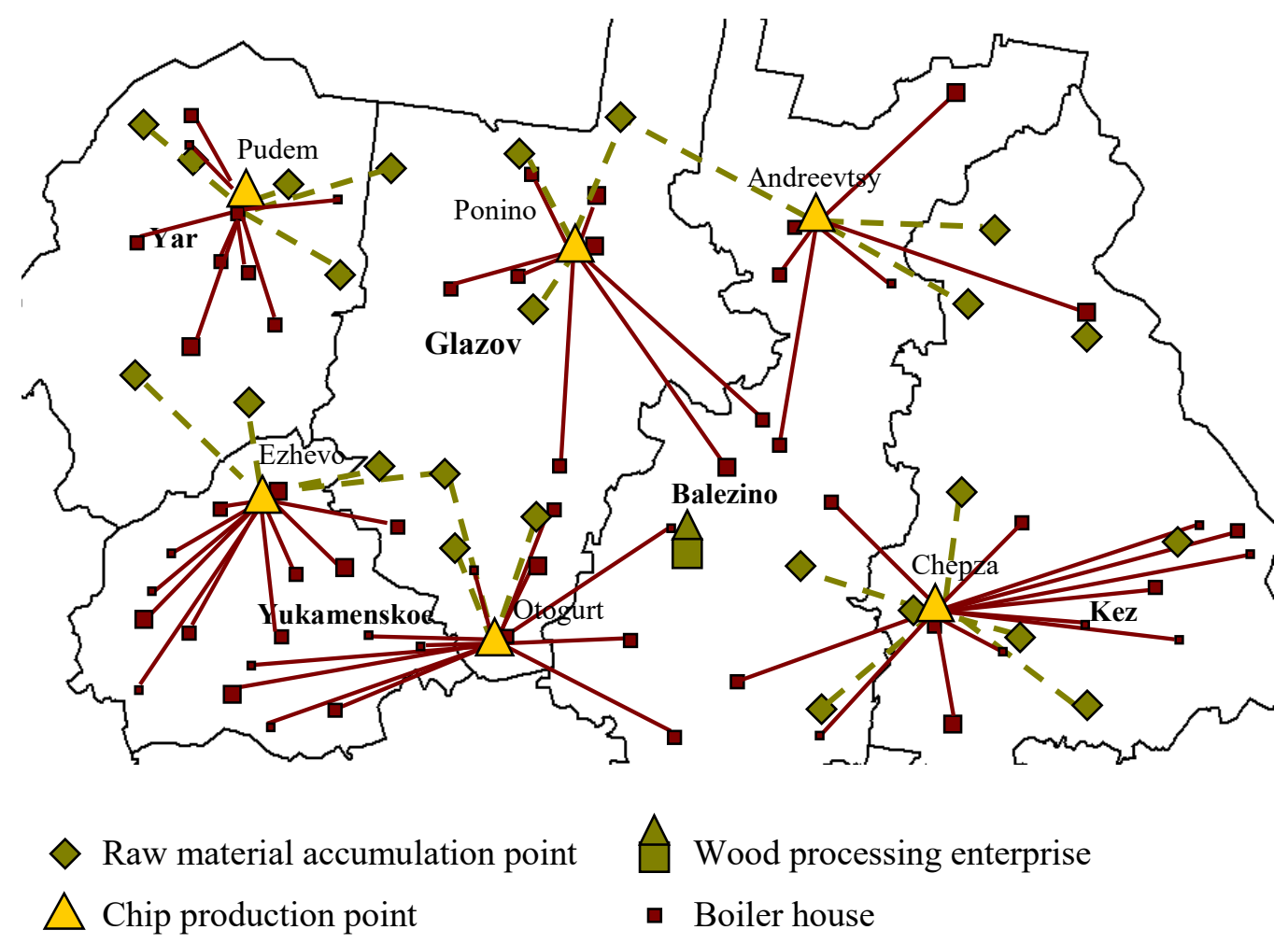

Figure 5: Optimal layout of wood fuel production points

The total production of wood chips was $9.905 \mathrm{t}$ f.e./year. The objective function value is 50.5 million rubles/year. The average cost of producing heat energy using wood fuels for all considered coal-fired boiler houses amounted to $897 \mathrm{rubles} / \mathrm{Gcal}$, which is significantly lower than the corresponding indicator for heat energy on coal, equal to $1.584 \mathrm{rubles} / \mathrm{Gcal}$ [7].

\section{Conclusion}

The problem of logistics planning for the use of renewable fuels in the energy complex was solved on the example of the Udmurt Republic. The technology used is the production of heat energy from wood waste. Logging and wood processing enterprises, which are a source of wood waste, wood waste processing stations, which produce chips and pellets, as well as coal-fired boilers, which generate heat energy, are considered as objects participating in the process of heat energy production. The structure of optimal placement of participants in the process of heat energy production from wood waste on the territory of the Udmurt Republic from the point of view of the criterion of minimizing the costs of its production and delivery to the consumer has been built. The restrictions in the form of tariffs for the transportation of wood waste, chips and pellets were also taken into account.

It was found that in the conditions of the Udmurt Republic, the organization of pellet plants turned out to be inappropriate. It was found that the optimal placement option assumes the presence of 6 wood chips preparation points. This makes it possible to provide fuel to all coal-fired boiler houses located in 
the region. The average cost of producing heat energy using wood fuels for all the boiler houses under consideration was $897 \mathrm{rubles} / \mathrm{Gcal}$, which is $76.6 \%$ lower than the corresponding indicator for heat energy obtained from coal.

\section{References}

[1] Carey King, Beyond the Competing Narratives on Energy, Growth, and Policy, The Economic Superorganism, Springer International Publishing (2021). doi: 10.1007/978-3-030-50295-9.

[2] E. Solomin, A. Ibragim, P. Yunusov, Renewable Energy Potential of Russian Federation, in: A. Radionov, A. Karandaev (Eds), Advances in Automation. RusAutoCon 2019, Lecture Notes in Electrical Engineering, volume. 641, Springer, Cham, 2020. doi: https://doi.org/10.1007/978-3030-39225-3 51.

[3] E. M. Kashin, R. R. Safin, V. N. Didenko, Generating Gas from Wood Waste as Alternative to Natural Gas in Package Boilers, in: A. Radionov, A. Karandaev (Eds), Advances in Automation. RusAutoCon 2019. Lecture Notes in Electrical Engineering, volume 641, Springer, Cham, 2020. doi: https://doi.org/10.1007/978-3-030-39225-3_53.

[4] M. S. Daskin, What You Should Know About Location Modeling, Naval Research Logistics, volume 55(4), 2008, pp. 283-294. doi:10.1002/nav.20284.

[5] A. Sokolov, V. Syunev, Decision Support System for Wood Fuel Production and Logistics, in: V. Murgul, M. Pasetti (Eds), International Scientific Conference Energy Management of Municipal Facilities and Sustainable Energy Technologies EMMFT 2018. EMMFT-2018 2018. Advances in Intelligent Systems and Computing, volume 983, Springer, Cham, 2019. doi: https://doi.org/10.1007/978-3-030-19868-8_83.

[6] K. V. Ketova, E. V. Trushkova, The solution of the logistics task of fuel supply for the regional distributed heat supply system, Computer Research and Modeling, 4(2), 451-470. doi: 10.20537/2076-7633-2012-4-2-451-470.

[7] I. G. Rusyak, V. K. Preshukhin, K. V. Ketova, S. A. Korolev, E. V. Trushkova, Development of the Concept of Fuel Supply Distributed Regional Heating System of Local Renewable Fuels, Energy Safety and Energy Economy, Energy Safety and Energy Economy 5 (2010) 14-20.

[8] T. Rapcsak, Smooth Nonlinear Optimization in Rn, Springer-Verlag, p. 376.

[9] Qi Dong. Tingxue Xu, Jikun Yang, Zhiheng Zhou, Research on Nonlinear Optimization Problem Based on Genetic Algorithm Theory, In book: Proceedings of the First Symposium on Aviation Maintenance and Management-Volume I, 2014, pp. 527-534. doi: 10.1007/978-3-642-542367 7_58.

[10] Paul Kang-Hoh Phua, Daohua Ming, Weiguo Fan, Yan Zhang, Parallel Algorithms for Solving Large-Scale Nonlinear Optimization Problems, in: X. Yang, K.L. Teo, L. Caccetta (Eds), Optimization Methods and Applications. Applied Optimization, volume 52, Springer, Boston, MA, 2001. doi: https://doi.org/10.1007/978-1-4757-3333-4_15. 